RU Сакральная лексика в татарском языке как языковой и культурный код

Юсупов А. Ф., Мухаметова И. И.

Аннотация. Цель исследования - изучение лексико-семантических особенностей сакральной лексики татарского языка в контексте национального мировоззрения. Научная новизна определяется семантическим осмыслением сакральной лексики в татарском языке, а также изучением данной лексико-семантической группы как языкового и культурного кода в контексте национального мировоззрения. В результате установлено: наличие такого большого количества лексем религиозной тематики свидетельствует о том, что сакральная лексика играет немаловажную роль в мировоззрении народа, и следовательно, в его образе жизни и языке. Лексический фонд языка, являющийся в настоящее время предметом многочисленных исследований лингвистов, необходимо рассматривать не только в качестве совокупности слов, присутствующих в языке, но и в качестве целостного понятия, отражающего культуру и менталитет народа.

\title{
EN Sacred Vocabulary in the Tatar Language as Language and Cultural Code
}

\author{
Yusupov A. F., Mukhametova I. I.
}

\begin{abstract}
The research aims to study lexico-semantic features of the sacred vocabulary of the Tatar language in the context of the national worldview. Scientific novelty of the work is accounted for by semantic understanding of the sacred vocabulary in the Tatar language, as well as by studying this lexico-semantic group as a language and cultural code in the context of the national worldview. As a result, it is determined that presence of such a large number of religious lexemes indicates that the sacred vocabulary plays a critical role in the people's worldview and, therefore, in their way of life and language. The lexicon of the language, which is currently a subject of numerous linguistic studies, must be considered not only as a set of words present in the language but also as a holistic concept that reflects the people's culture and mentality.
\end{abstract}

\section{Введение}

В современной лингвистической науке весьма активизировались исследования, направленные на изучение языка в контексте этнической культуры. Как известно, язык служит средством накопления, хранения и трансляции информации об историко-культурной эволюции этноса. «Сведения о культурной, материальной жизни народа могут быть представлены различными семиотическими системами, относящимися к определенному культурному коду. В рамках национальной культуры человек может мыслить и представить единицами национального языка свое видение мира» [4, с. 20]. В некоторых единицах эта информация для современного носителя языка имплицитна, скрыта вековыми трансформациями, может быть извлечена лишь в результате всестороннего изучения не только языковой, но и культурной семантики.

В формировании и развитии татарского языка как части духовной культуры народа огромную роль сыграла мусульманская религия, которая способствовала формированию новой тюрко-татарской культуры. Тюрко-татарская культура возникла в результате синтеза исторического опыта доисламского периода народа и арабско-персидской цивилизации, которая, «в отличие от культур мусульманских стран, имела свою специфику» [Там же, с. 111].

История становления татарского народа так или иначе связана с формированием определенного религиозного мировоззрения, которое со временем стало оказывать влияние не только на культуру поведения татар, но и на словарный запас татарского языка. «На протяжении многих веков тюркский письменно-литературный язык оснащался большим количеством инородных лексических единиц и грамматических элементов» [10, с. 214], закреплению которых в словарном составе национального языка «способствовала суфийская поэзия, пропитанная арабо-персидскими элементами и оказавшая сильное воздействие на развитие письменного литературного языка того времени» [11, с. 100]. В связи с этим в настоящее время большинство 
лингвистов сходятся во мнении, что религиозные лексические единицы татарского языка отражают также и этнокультурные особенности татар, что обуславливает важность их подробного изучения.

Проблема функционально-семантических особенностей религиозной лексики в языке является актуальной для татарского языкознания. Исследование этимологии лексических единиц позволяет провести анализ специфики становления духовной культуры татарского народа и особенностей формирования его менталитета на протяжении веков.

Для достижения указанной цели нами были поставлены следующие задачи: 1) посредством сплошной выборки выбрать сакральные лексические единицы, которые активно употребляются в татарском языке; 2) провести тематический и статистический анализ лексем, относящихся к каждой из тематических групп; 3) провести семантический анализ лексем и интерпретировать значение сакральной лексики. В соответствии с этим нами была проведена тематическая классификация лексики, связанной с религией, у татарского народа.

Применительно к проблематике исследования результативно используется комплекс существующих базовых методов исследования: описательный, сравнительно-исторический, сопоставительный, статистический, приемы частичной и сплошной выборки исследуемого материала.

Теоретической базой исследования послужили работы татарских языковедов: Г. Р. Галиуллиной [4], в которой татарский язык исследуется в рамках лингвокультурологической проблематики, М. Р. Саттаровой [7], А. Ф. Юсупова [10; 12], посвященные описанию сакральной и суфийской лексики в синхронном и диахронном аспектах, а также труды отечественных учёных И. М. Кобозевой [5], Д. И. Рыжкова [6], В. И. Шаховского [9], в которых раскрываются понятия «семантическое поле» и «семантический потенциал религионимов», определяются основные направления осмысления религиозной лексики.

При анализе лексических единиц были использованы различные типы словарей, позволяющие установить происхождение и верную интерпретацию лексем: «Толковый словарь татарского языка» [8], «Этимологический словарь татарского языка» [2], «Арабско-русский словарь» [3], «Исламский энциклопедический словарь» [1].

Практическая значимость работы заключается в том, что результаты исследования могут использоваться в вузовской практике: в лекционных и семинарских занятиях по татарскому языкознанию, при написании курсовых и выпускных квалификационных работ, а также при изучении функционально-семантических особенностей религиозной лексики в татарском языке.

\section{Специфика трактовки религиозной лексики в современной татарской лексикологии}

Значительную часть словарного состава татарского языка составляет сакральная лексика - религионимы, которые относятся к различным историческим периодам: язычества, христианства и ислама. В рамках данной статьи анализируется только та часть религиозной лексики, которая относится к исламу и связана с мусульманским мировоззрением.

Как отмечают исследователи, в Толковом словаре татарского языка [8] фиксируется достаточно большое количество религионимов - «примерно 500 лексических единиц, которые в той или иной степени отражают религиозные представления, из них приблизительно 400 - имена существительные» [7]. М. Р. Саттарова классифицирует данные религионимы по следующим лексико-тематическим группам: понятия, которые связаны с верой в загробную жизнь; лексемы, которые отражают религиозные моральные нормы; названия религиозных праздников; обращения к Богу; названия строений и их элементов; названия элементов небесной иерархии; названия иерархии священнослужителей; наименования лиц, которые так или иначе относятся к религиозной деятельности и т.д. [Там же].

Лексемы, которые входят в большинство выделенных тематических групп, чаще всего называют понятия духовной культуры и представляются заимствованиями. К примеру, можно выделить такие арабские слова, как жәннәт (рай), тәкъдир (судьба), мөфти (неверный) и др. Важно также подчеркнуть, что не все перечисленные единицы относятся к активному лексическому фонду современного татарского языка. К примеру, тәкъдир (судьба), госел бүлмәсе (комната для омовения) и др. достаточно редко употребляются в повседневной жизни, в связи с чем их часто заменяют тюрко-татарским вариантом употребления: язмыш (судьба), юыну бүлмәсе (комната для умывания) и др.

Необходимо также отметить, что в некоторых случаях с целью передачи полной семантики понятий употребляются тюрко-татарские лексические единицы, к примеру, дин башлыгы (духовный лидер) и др. Наиболее ярко данная тенденция проявляется в использовании глаголов: азан дйтү (возглашать призыв к молебну), дога кылу (читать молитву, молиться). Использование тюрко-татарских слов в таком варианте совместно с арабо-персидскими подтверждает тот факт, что в течение веков религиозные понятия в полной мере освоились и стали принимать активное участие в словообразовании татарского языка. Примером этого являются такие выражения, как ахыр заман (конец света) или сират күпере (мост над адом).

Далее целесообразно проанализировать количество лексем, относящихся к каждой из вышеприведенных тематических групп, на основании выборки исследования (500 лексем). Результаты проведенного анализа представлены на Рисунке 1.

Согласно результатам проведенного исследования, наибольшую часть сакральной лексики, присутствующей в Толковом словаре татарского языка [8], составляют слова, связанные с верой татар в загробную жизнь (24\%). Второй по численности тематической группой является лексика, отражающая религиозные моральные нормы татарского народа (18\%). Слова, которые относятся к таким тематическим группам, как «лексика, связанная 
с обращениями к Богу», «названия строений и их элементов», а также «названия иерархии священнослужителей», составляют по 12\% от общей выборки. В ходе анализа также было обнаружено по 9\% лексем, которые называют элементы небесной иерархии и лиц, занимающихся религиозной деятельностью. Самой малочисленной группой сакральной лексики в Толковом словаре татарского языка являются слова, называющие религиозные праздники (4\% от общей выборки).

\section{Тематические группы сакральной лексики}

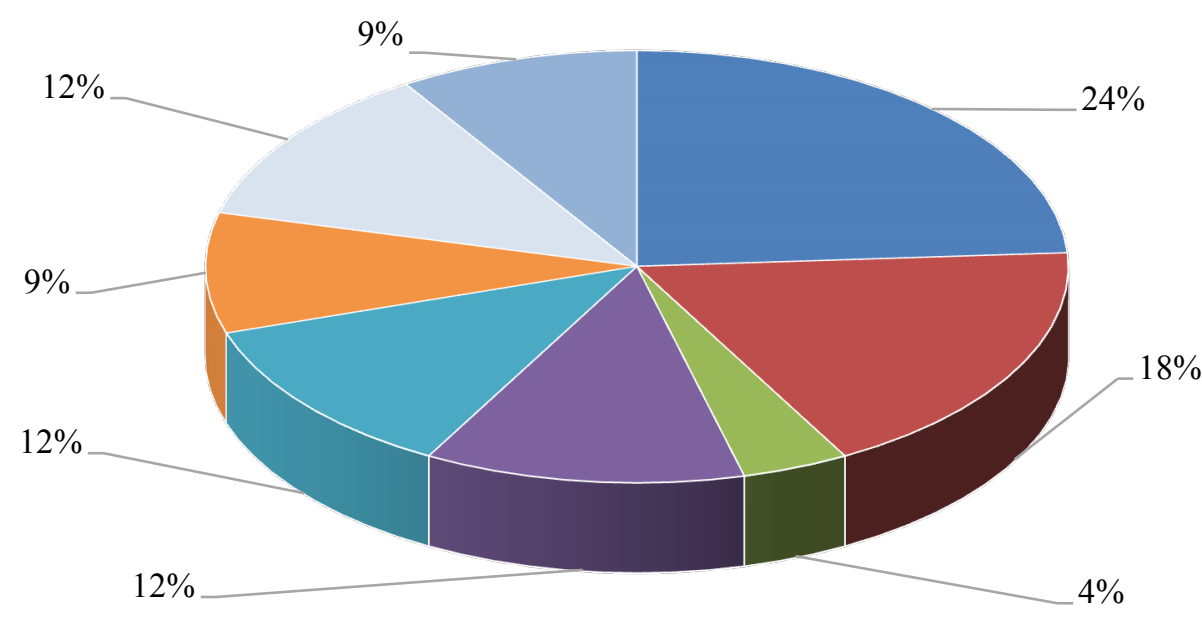

\footnotetext{
- Понятия, которые связаны с верой в загробную жизнь - Религиозные моральные нормы

- Названия религиозных праздников

- Обращения к Богу

- Названия строений и их элементов

• Названия элементов небесной иерархии

Названия иерархии священнослужителей

- Лица, занимающиеся религиозной деятельностью
}

Рисунок 1. Анализ численности слов сакральной лексики, относящихся к различным тематическим группам

Безусловно, выделенные тематические группы не исчерпывают все существующие в татарском языке религиозные лексемы. В частности, также в Толковом словаре встречаются следующие религионимы:

- комган/кумган (кувшин с носиком и ручкой для умывания и религиозных омовений). Тематическая группа - ритуальные предметы;

- азан (призыв к молебну). Тематическая группа - ритуальные обряды;

- aять (стих Корана). Тематическая группа - ритуальные тексты;

- изге ай (священный месяц). Тематическая группа - календарные наименования.

Важно подчеркнуть, что в современном татарском языке, помимо самостоятельных лексических единиц, можно встретить также фразеологизмы, отражающие религиозные представления народа.

\section{Проблемы семантического осмысления сакральной лексики}

Главное внутриязыковое условие, которое призвано обеспечивать развитие (динамику) значений, - существование соответствующего семантического пространства [6, с. 73]. Как известно, термин «семантическое поле» в современной лингвистике трактуется как совокупность «лингвистических единиц, объединяющих общность содержания и отражение понятийного, предметного или функционального сходства называемых явлений» [5, с. 99].

Главная сложность заключена в том, что в семантическом пространстве нескольких языков общность содержания нередко распределяется по различным «участкам». Кроме того, использование татарских религионимов «в составе различных фразеологизмов свидетельствует о более широких объединениях, которые, вместе с вышеперечисленными сходствами, включают в себя и эмотивную общность» [9, с. 47]. Динамика значений религионимов позволяет сделать вывод о том, что они выходят за пределы соответствующего семантического поля. В связи с этим целесообразным представляется «выделение семантической сферы функционирования, которые классифицируются на ближайшие (БССФ) и дальнейшие (ДССФ)» [6, с. 74].

Определив основные направления осмысления религиозной лексики в татарском языке, далее целесообразно провести семантический анализ некоторых из выделенных ранее религионимов.

Aхирәт (загробная жизнь) - этимологически данная лексема происходит от араб. الآخر “axirätun” - конец, окончание; загробная жизнь [3, с. 27]. Термин ахира в исламской терминологии обозначает будущую жизнь, потусторонний мир [1, с. 40], чаще всего лексема «ахирәт» переводится на татарский язык в следующих значениях: «конец», «то, что бывает после», «последний день». Следовательно, главная БССФ слова «ахирәт»- 
потусторонний мир, жизнь после смерти. Если анализировать специфику употребления данного слова в татарском языке, то можно говорить об отсутствии эмотивного компонента.

Раббе (رَ - Господь Бог, Боже). В настоящее время среди исследователей нет единства касательно происхождения слова «раббе» [2, с. 318], однако некоторые специалисты считают, что этимология данной лексемы связана с древнеболгарским словом «рабъ» в дословном переводе «зависимый». Следует отметить, что в арабском языке слово رَبّ “rabbun” функционирует в нескольких значениях: 1) Господь; 2) господин; 3) государь; 4) владелец; хозяин; глага [3, с. 281], а в татарском языке «раббе» трактуется как «Аллаһ, Ходай» - Всевышний, Господь, Бог, Боже [8, б. 438].

Шоригать (араб. شَرَعَة “šrifatun” - законоположение, церковный закон; шариат [3, с. 400]). В исламской терминологии шариат - прямой, правильный путь [1, с. 309]. Этот термин имеет широкое значение: этимологически данная лексема происходит от араб. “šar’’at” - свод религиозных правил [2, с. 421]. Наиболее точное значение слова, которое представлено в Толковом словаре татарского языка - совокупность религиозных и юридических норм мусульманского феодального права, письменный свод мусульманских законов [8, б. 693-694].

При семантическом осмыслении данной лексемы можно говорить о наличии эмотивного компонента. В частности, «шәригать» может использоваться в прямом значении (нормы шариата), а также в переносном для оценки поведения человека (он живет не по законам шариата!).

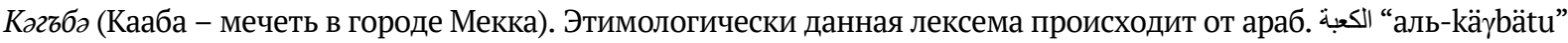
и функционирует в нескольких значениях: 1) куб; 2) строение в виде куба; 3) Кааба [3, с. 691]. Кааба - небольшое строение, которое находится в центре священного мусульманского храма Масджид аль-Харам [1, с. 150]. Наиболее точное значение слова, которое представлено в Толковом словаре татарского языка, - мусульманская святыня в виде кубической постройки во внутреннем дворе Заповедной Мечети (Мекка).

Большинство исследователей сходятся во мнении, что «Кәгъбә» имеет символическое значение, поскольку само название обусловлено формой данного религиозного здания.

Ахун (архирей). Этимологически данная лексема происходит от казах. “akyn” - старший мулл [2, с. 69]. Наиболее точное значение слова, которое представлено в Толковом словаре татарского языка, - мусульманский богослов, ученый мулла. Если анализировать специфику употребления данного слова в татарском языке, то можно говорить об отсутствии эмотивного компонента.

\section{Заключение}

Таким образом, в Толковом словаре татарского языка присутствует около 500 единиц религиозной лексики, которые условно можно классифицировать на 8 тематических групп: понятия, которые связаны с верой в загробную жизнь; лексемы, которые отражают религиозные моральные нормы; названия религиозных праздников; обращения к Богу; названия строений и их элементов; названия элементов небесной иерархии; названия иерархии священнослужителей; наименования лиц, которые так или иначе относятся к религиозной деятельности. Для полной передачи семантики достаточно часто употребляются тюрко-татарские лексические единицы, что свидетельствует о том, что религиозные представления со временем стали способствовать словообразованию татарского языка.

В настоящее время одним из важнейших лингвистических понятий является термин «семантическое поле», которое необходимо рассматривать в качестве совокупности лингвистических единиц, коих объединяет общность содержания и отражение понятийного, предметного или функционального сходства называемых явлений. Также в рамках семантического осмысления религиозной лексики немалую важность приобретает понятие семантического функционирования, которое можно рассматривать в качестве совокупности смысловых полей, вербализирующих тот или иной тематический блок. На основании результатов проведенного исследования нами было выявлено, что с точки зрения семантики большинство татарских религионимов являются заимствованиями из других языков (преимущественно арабского), которые с учетом мировоззрения и религиозных представлений татарского народа несколько видоизменили свое значение. В свою очередь, у большинства татарских религионимов присутствует эмотивный компонент, иными словами, их значение может меняться в соответствии с контекстом высказывания. Вышеприведенные особенности также определяют значимость изучения сакральной лексики, в том числе и для понимания этнокультурных особенностей татарского народа.

Таким образом, активность религиозной лексики свидетельствует о том, что сакральная лексика играет немаловажную роль в мировоззрении народа. Следует отметить, что лексический фонд языка является не только совокупностью слов, присутствующих в языке, но и выступает в качестве целостного понятия, отражающего культуру и менталитет народа.

Перспективы дальнейшего исследования проблемы мы видим в более детальном изучении сакральной лексики и ее функционального потенциала в диахронном аспекте.

\section{Источники | References}

1. Али-заде А. А. Исламский энциклопедический словарь. М.: Ансар, 2007. 340 с.

2. Ахметьянов Р. Г. Этимологический словарь татарского языка: в 2-х т. Казань: Магариф-Вакыт, 2015. Т. 1. А - Л. 543 c. 
3. Баранов Х. К. Арабско-русский словарь: ок. 42000 слов. Изд-е 7-е, стер. М.: Рус. яз., 1989. 928 с.

4. Галиуллина Г. Р. Татарские личные имена в контексте лингвокультурных традиций. Казань: Изд-во Казан. гос. ун-та, 2008. 352 с.

5. Кобозева И. М. Лингвистическая семантика: учеб. пособие. М.: Эдиториал УРСС, 2000. 352 с.

6. Рыжков Д. И. Семантическое развитие христианской религиозной лексики: на материале латинского, французского, итальянского, английского и русского языков: дисс ... к. филол. н. Тверь, 2017. 149 с.

7. Саттарова М. Р. Сакральная лексика современного татарского языка (на материале толкового словаря) [Электронный ресурс] // Современные проблемы науки и образования. 2014. № 6. URL: http://scienceeducation.ru/ru/article/view?id=15301 (дата обращения: 25.05.2021).

8. Татар теленең аңлатмалы сүзлеге. Казан: «Матбугат йорты» нәшр., 2005. 848 б.

9. Шаховский В. И. Соотносится ли эмотивное значение слова с понятием? // Вопросы языкознания. 1987. № 5. С. 47-59.

10. Юсупов А. Ф. Заимствованные имена прилагательные в языке татарских суфийских произведений // Филологические науки. Вопросы теории и практики. 2013. № 10 (28). С. 214-217.

11. Юсупов А. Ф. Многовариативность старотатарского литературного языка XIX века // Филология и культура. 2012. № 3 (29). С. 99-103.

12. Юсупов А. Ф. Суфийская лексика в языке поэтических произведений XIX века // Исламоведение. 2015. T. 6. № 3 (25). С. 71-77.

\section{Информация об авторах | Author information}

RU Юсупов Айрат Фаикович ${ }^{1}$, к. филол. н., доц. Мухаметова Ильхамия Ильязовна ${ }^{2}$

${ }_{1,2}^{2}$ Казанский (Приволжский) федеральный университет

EN Yusupov Ayrat Faikovich ${ }^{1}, \mathrm{PhD}$

Mukhametova Ilkhamiya Ilyazovna ${ }^{2}$

${ }^{1,2}$ Kazan Federal University

${ }^{1}$ faikovich@mail.ru, ${ }^{2}$ ilhamiyai@mail.ru

\section{Информация о статье | About this article}

Дата поступления рукописи (received): 14.05.2021; опубликовано (published): 30.06.2021.

Ключевые слова (keywords): сакральная лексика; религиозная лексика; языковой и культурный код; религионимы; sacred vocabulary; religious vocabulary; language and cultural code; religionyms. 